\title{
The stress characteristics of plate-fin structures at the different operation parameters of LNG heat exchanger
}

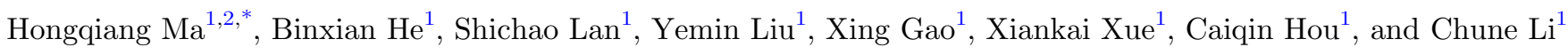 \\ ${ }^{1}$ School of Civil Engineering, Lanzhou University of Technology, Lanzhou - PR China \\ ${ }^{2}$ Sinopec Petroleum Engineering Zhongyuan Corporation, Puyang - PR China
}

Received: 20 October 2017 / Accepted: 5 March 2018

\begin{abstract}
In this paper, the stresses of plate-fin structures at the different operation parameters were analyzed in actual operation process of LNG plate-fin heat exchanger based on finite element method and thermal elastic theory. Stress characteristics of plate-fin structures were investigated at the different operation parameters of that. The results show that the structural failure of plate-fin structures is mainly induced by the maximum shear stress at the brazing filler metal layer between plate and fin while by the maximum normal stress in the region of brazed joint near the fin side. And a crack would initiate in brazed joint near the fin side. The maximum normal stress is also main factor to result in the structural failure of plate-fin structures at the different temperature difference (between Natural Gas (NG) and Mixture Refrigerant (MR)), MR temperature and NG pressure of LNG heat exchanger. At the same time, the peak stresses obviously increase as the temperature difference, MR temperature and NG pressure increase. These results will provide some constructive instructions in the safe operation of LNG plate-fin heat exchanger in a large-scale LNG cold-box.
\end{abstract}

\section{Introduction}

Plate-Fin Heat Exchanger (PFHE), as a main heat exchange equipment, has been widely used in small-scale LNG plants while rarely in large-scale LNG plants as main cryogenic heat exchanger in the world (Kuznetsov and Shamirzaev, 2007; Ligterink et al., 2012; Liu and Winterton, 1991). PFHE is consisted of plate-fin structures and usually installed in a LNG cold-box in largescale LNG plants. Therefore, the plate-fin structure is the key component in the PFHE which is the key equipment in a large-scale LNG cold-box. Its security is affected by stress characteristics of plate-fin structures at the different operation conditions of LNG PFHE in largescale LNG plants (Mizokami et al., 2013; Picard et al., 2006). However, the stress characteristics of plate-fin structures are still far from well understood at the different operation conditions of LNG PFHE in large-scale LNG plants.

At present, many studies have been done on stress characteristics of plate-fin structures in heat exchanger. But most of the investigations have been focused on residual stress of plate-fin structures in brazing process of plate-fin heat exchanger which was made of stainless steel

\footnotetext{
* Corresponding author: mhq2014@sina.com
}

(Jiang et al., 2010, 2011a, 2011b, 2011c, 2012). At the same time, in our previous work, the stress characteristics of plate-fin structures were also analyzed in the cool-down or heat-up process of LNG PFHE in a large-scale LNG cold-box (Ma et al., 2016a; Ma et al., 2014) based on finite element method and thermal elastic theory. The results show that a crack initiates in the brazed joint in the cooldown or heat-up process of LNG PFHE because that the stresses rapidly change and consistently reach the peak value in this region. Meanwhile, the stress of plate-fin structures is obviously influenced by the temperature difference between Natural Gas (NG) and Mixture Refrigerant (MR) while the influence of the temperature drop or rise rate is slight as the temperature drop or rise rate of NG is the same as that of MR. In order to ensure the structural safety of plate-fin structures in actual operation process of LNG PFHE and guide the structural design, stress characteristics of plate-fin structures are analyzed at the different structure parameters based on finite element method and thermal elastic theory. The results show that the stresses of plate-fin structures are obviously impacted by the brazing seam thickness, fin thickness and fin distance and it is mainly induced by the direct stress in $y$ direction(Ma et al., 2016b). In these investigations, the peak value of equivalent stress, the direct stresses along $x, y$ and $z$ directions and the shear stress on $x-y$ plane and $y-z$ plane were analyzed to explain the stress characteristics of plate-fin structures in LNG 


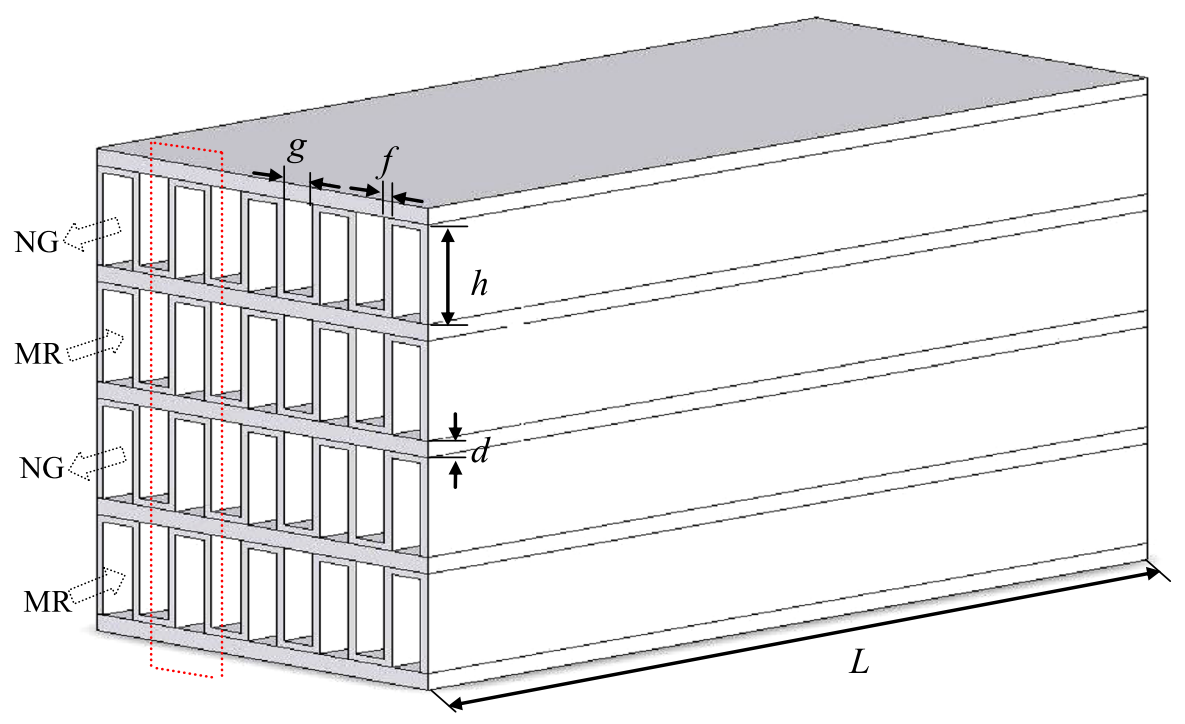

Fig. 1. The diagram of plate-fin structures.

Table 1. Structural parameters (From the bottom plate to top is from No. 1 to No. 5).

\begin{tabular}{lllllll}
\hline $\begin{array}{c}\text { Layer } \\
\text { number }\end{array}$ & $\begin{array}{c}\text { Plate thickness } \\
d(\mathrm{~mm})\end{array}$ & $\begin{array}{c}\text { Fin number } \\
\text { in } 100 \mathrm{~mm}\end{array}$ & $\begin{array}{c}\text { Fin thickness } \\
f(\mathrm{~mm})\end{array}$ & $\begin{array}{c}\text { Fin height } \\
h(\mathrm{~mm})\end{array}$ & $\begin{array}{c}\text { Effective length } \\
L(\mathrm{~mm})\end{array}$ & $\begin{array}{c}\text { Brazing seam } \\
\text { thickness }(\mathrm{mm})\end{array}$ \\
\hline No. 1 & 1.6 & 100 & 0.4 & 6 & 2.5 & 0.1 \\
No. 2 & 1.6 & 100 & 0.4 & 6 & 2.5 & 0.1 \\
No. 3 & 1.6 & 100 & 0.4 & 6 & 2.5 & 0.1 \\
No. 4 & 1.6 & 100 & 0.4 & 6 & 2.5 & 0.1 \\
No. 5 & 1.6 & - & - & - & 2.5 & 0.1 \\
\hline
\end{tabular}

PFHE. In fact, the direct stresses along $x, y$ and $z$ directions and the shear stresses on $x-y$ plane and $y$ - $z$ plane are distinct in different coordinate systems. According to material mechanics, the maximum normal stress $\left(\sigma_{\max }\right)$ and maximum shear stress $\left(\tau_{\max }\right)$ are always consistent in different coordinate systems. Therefore, it is necessary to explain the stress characteristics of plate-fin structures in LNG PFHE. In other words, it is necessary that the maximum normal stress and maximum shear stress of plate-fin structures are analyzed in operation process of LNG PFHE based on the thermal elastic theory in order to investigate the stress characteristics of plate-fin structures in LNG PFHE. However, now it is lack for the analysis of the maximum normal stress and maximum shear stress of plate-fin structures in LNG PFHE.

In this work, the direct coupling method was adopted to simulate the stress characteristics of plate-fin structures at the different operation parameters in LNG PFHE. The distributions of the maximum normal stress $\left(\sigma_{\max }\right)$, maximum shear stress $\left(\tau_{\max }\right)$ and equivalent stress $\left(\sigma_{r}\right)$ in plate-fin structures were analyzed in actual operation process. And the influence of operation parameters was investigated for the peak value of maximum normal stress and maximum shear stress in the concentration region of stress in the total LNG plate-fin structures.

\section{Finite element model analysis}

\subsection{The model description}

In the LNG PFHE, plate-fin structures mainly consist of fins, plate (Carey and Mandrusiak, 1986; Manglik and Bergles, 1995), as shown in Figure 1. Table 1 is the detailed structural parameters of plate-fin structures in LNG PFHE of a LNG cold-box in large-scale LNG plants. Figure 1 shows that the structural shape of plate-fin structures is cyclical repeatability and complexity in LNG PFHE. In order to simplify the analysis model in the numerical simulation, some issues would be assumed. In this paper, the influence of layers number is ignored for stress characteristics of plate-fin structures. The flow of NG is assumed to be alternating and counterflow with mixture refrigerant $\mathrm{MR}$, as shown in Figure 1. At the same time, the change of fluid temperature is ignored because that is very small in a very short length $(\mathrm{L})$ along the length direction of plate-fin structures. Therefore, only one unit of plate-fin structures which consists of four layers plate and fin, was analyzed in a very short length $(L)$ at the different operation parameters in LNG heat exchanger, as dotted lines shown in Figure 1. Figure 2a shows the simplified model of plate-fin structures. Figures $2 \mathrm{~b}$, c display the local 

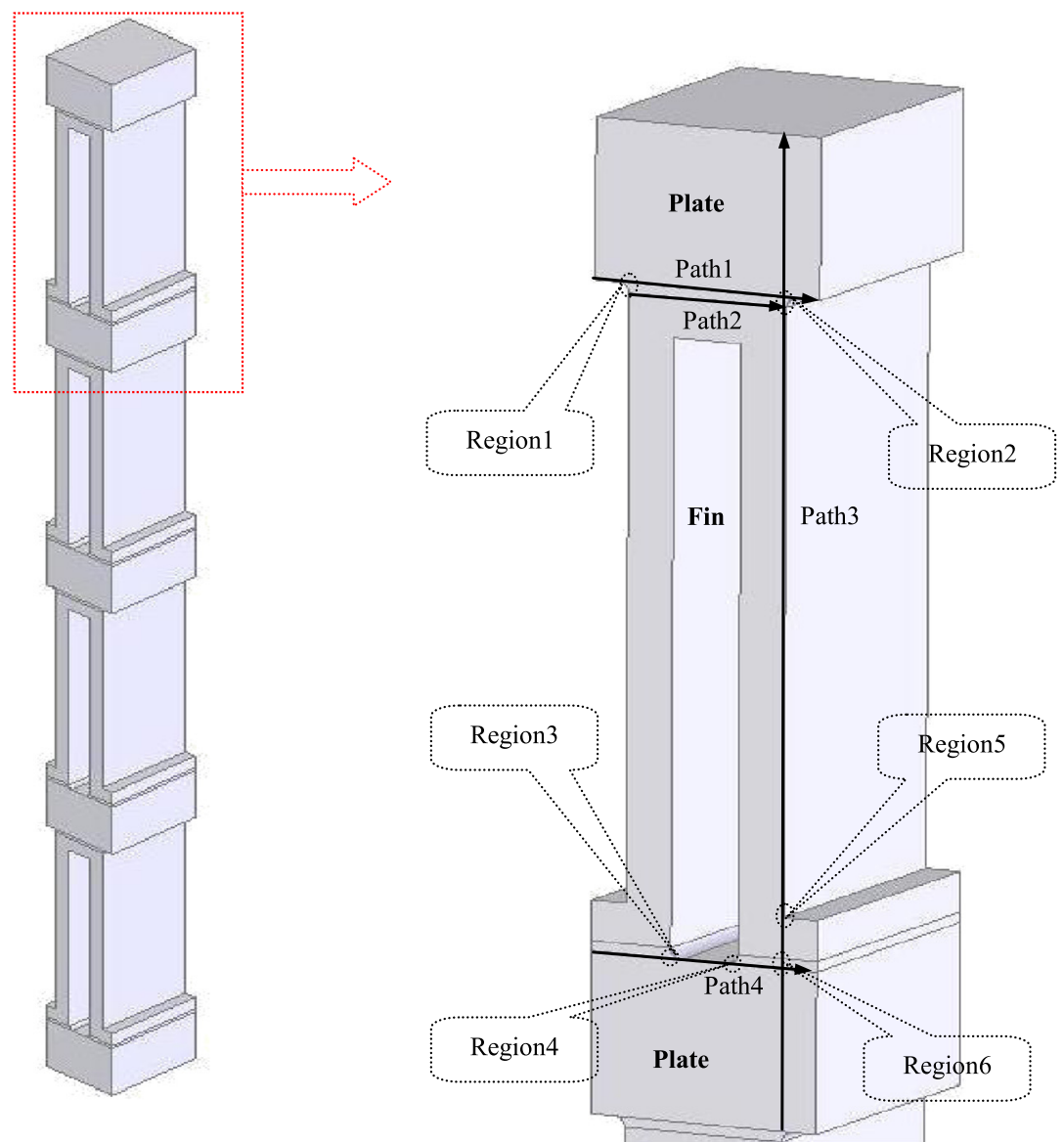

(a) The plate-fin structure model

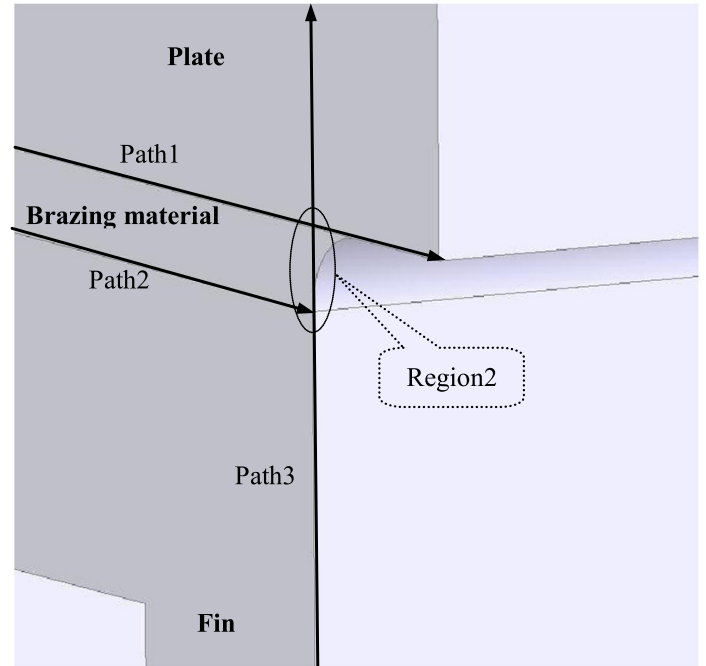

(b) The local structure of region 2

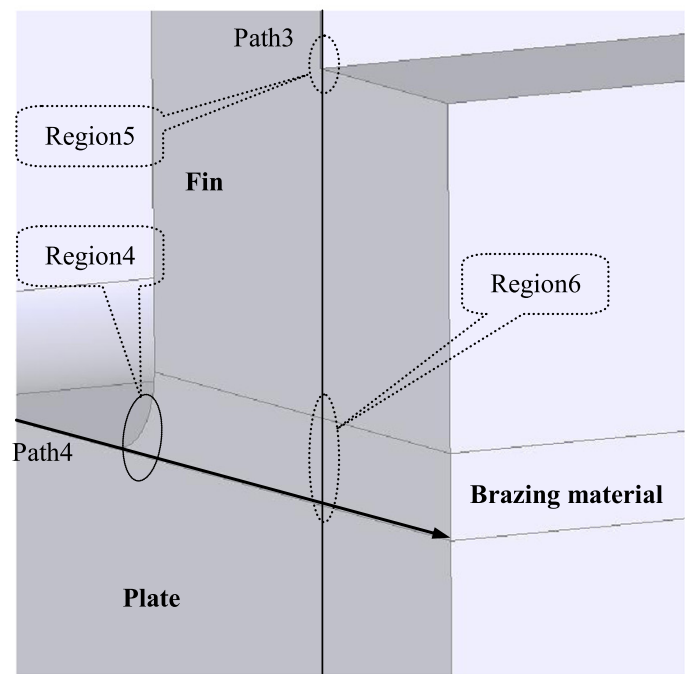

(c) The local structure of regions 4, 5 and 6

Fig. 2. The simplified plate-fin structure model and local structure.

structure of region 2 and regions 4, 5 and 6 in Figure 2a, respectively.

\subsection{Material properties}

According to the literature (Ma et al., 2016b), the materials of plate-fin structures are treated as isotropic and linear elastic. At the same time, in order to get fine results, the expansion coefficient and elastic modulus are assumed to be temperature dependent for the AL3003 and the AL4004 (The fin and plate is assumed to be AL3003 and the brazing material is AL4004). Table 2 is the detailed material properties of AL3003 and AL4004 used in the simulations. 
Table 2. Material parameters used in FEM simulation.

\begin{tabular}{|c|c|c|c|c|c|c|c|c|}
\hline Material & $\begin{array}{l}\text { Temperature, } \\
\mathrm{K}\end{array}$ & $\begin{array}{l}E, \\
\mathrm{GPa}\end{array}$ & $\begin{array}{l}C E T \\
\left(10^{-6}\right), 1 / \mathrm{K}\end{array}$ & $\begin{array}{l}\text { Poisson's } \\
\text { ratio }\end{array}$ & $\begin{array}{l}\text { Yield } \\
\text { strength MPa }\end{array}$ & $\begin{array}{l}\text { Specific heat, } \\
\mathrm{J} /(\mathrm{kg} \cdot \mathrm{K})\end{array}$ & $\begin{array}{l}\text { Density, } \\
\mathrm{kg} / \mathrm{m}^{3}\end{array}$ & $\begin{array}{l}\text { Conductivity, } \\
\mathrm{W} /(\mathrm{m} \cdot \mathrm{K})\end{array}$ \\
\hline & 305 & 68.9 & 22.4 & & & & & \\
\hline & 250 & 70.6 & 19.7 & & & & & \\
\hline & 195 & 72.4 & 16.9 & 0.33 & 145 & 962 & 2740 & 159 \\
\hline & 175 & 73.2 & 15.9 & & & & & \\
\hline \multirow[t]{4}{*}{ AL3003 } & 145 & 74.5 & 14.4 & & & & & \\
\hline & 305 & 94.6 & 15.1 & & & & & \\
\hline & 250 & 96.4 & 14.9 & & & & & \\
\hline & 195 & 98.2 & 14.7 & 0.35 & 142 & 864 & 2710 & 155 \\
\hline \multirow[t]{2}{*}{ AL4004 } & 175 & 98.8 & 14.6 & & & & & \\
\hline & 145 & 99.6 & 14.5 & & & & & \\
\hline
\end{tabular}

\subsection{Analysis strategy}

In ANSYS software, the thermal-mechanical coupling analysis for stress mainly includes the sequentially coupled and directly coupled (Khan et al., 2011; Zhao et al., 2012). For the sequentially coupled, the heat transfer process is firstly calculated by the ANSYS software. The temperature distribution calculated by that is used as the body loads in the mechanics analysis. For the directly coupled, the thermal and mechanical will be simultaneously calculated in the ANSYS software. In this work, the interaction between temperature field and strain field is considered because of the relatively large deformation on plate-fin structures. Therefore, the SOLID5 element for both plates and fins is adopted and the directly coupling method based on the thermal elastic theory is used to analyze the stress characteristics of plate-fin structures at the different operation parameters in LNG PFHE.

The convective heat transfer boundary is applied between the NG or MR and the wall of plate-fin structures to simulate the heat transfer process with phase change between the NG or MR and the wall of plate-fin structures in LNG PFHE. The cyclical symmetry boundary on the leftmost and rightmost surfaces is applied to simulate the periodicity and symmetry of plate-fin structures in LNG PFHE. The NG and MR operating pressure is adopted to simulate the interaction between the NG or MR and the wall of plate-fin structures.

At the same time, the computational domain is discretized into hexahedral finite control volumes using a mesh so as to decrease the grid numbers and improve the computation efficiency. The influence of the number on mesh cells for the simulation results is also done according to the method in literature(Ma et al., 2016a). The total number of mesh cells used in the paper was 141000 according to the calculation accuracy and efficiency. ANSYS Parametric Design Language was adopted to program the above simulation process. And the analysis method used in this paper is also validated by the experimental data in literature (Ma et al., 2014).

According to the von Mises yield criterion, the plastic yield failure of plate-fin structures may occur in operation process when the equivalent stress (von Mises stress) is more than the allowable stress. In other words, the initial cracking damage may be happened at the location of platefin structures which the equivalent stress reaches peak value. Therefore, in this paper, the equivalent stress of plate-fin structures is also be analyzed at the different operation parameters in LNG heat exchanger.

\section{Results and discussion}

\subsection{Stress distribution}

In liquefied heat exchanger of large-scale LNG cold-box, the NG is cooled from $210 \mathrm{~K}$ to $150 \mathrm{~K}$ and becomes liquid from the gas by condensation heat transfer at the NG pressure $P_{\mathrm{NG}}=7.1 \mathrm{MPa}$ and the $\mathrm{MR}$ is heated from $155 \mathrm{~K}$ to $215 \mathrm{~K}$ and vaporized by the boiling heat transfer at the MR pressure $P_{\mathrm{MR}}=0.4 \mathrm{MPa}$. According to the design condition, the heat transfer coefficient between NG and the wall of plate-fin structures is $1500 \mathrm{~W} /\left(\mathrm{m}^{2} \cdot \mathrm{K}\right)$ at the NG temperature $T_{\mathrm{NG}}=155 \mathrm{~K}$ and the NG pressure $P_{\mathrm{NG}}=$ $7.1 \mathrm{MPa}$; the MR heat transfer coefficient between NG and the wall of plate-fin structures is $1000 \mathrm{~W} /\left(\mathrm{m}^{2} \cdot \mathrm{K}\right)$ at the MR temperature $T_{\mathrm{MR}}=150 \mathrm{~K}$ and the $\mathrm{MR}$ pressure $P_{\mathrm{MR}}=0.4 \mathrm{MPa}$. Therefore, the stress distribution of plate-fin structures in a very short length near the NG entrance of the above liquefied heat exchanger is analyzed at the above parameters of the actual operation process.

For the sake of a better understanding, four reference paths were selected, as marked in Figure 2. Figures 3-8 present the distributions of the maximum normal stress, maximum shear stress and equivalent stress along the four reference paths in plate-fin structures at temperature difference $\Delta T=5 \mathrm{~K}$ between NG and MR, heat transfer coefficient $\quad h_{\mathrm{NG}}=1.5 \mathrm{~kW} /\left(\mathrm{m}^{2} \cdot \mathrm{K}\right), \quad h_{\mathrm{MR}}=1 \mathrm{~kW} /\left(\mathrm{m}^{2} \cdot \mathrm{K}\right)$, fluid pressure $P_{\mathrm{NG}}=7.1 \mathrm{MPa}, P_{\mathrm{MR}}=0.4 \mathrm{MPa}$. Figures 3 and 4 exhibit the distribution of the maximum normal stress, maximum shear stress and equivalent stress along paths 1 and 2, respectively. Paths 1 and 2 are located at the interface between the brazing filler metal and the plate and between the brazing filler metal and the fin, respectively. It can be seen clearly that the maximum normal stress, maximum shear stress and equivalent stress are symmetri- 


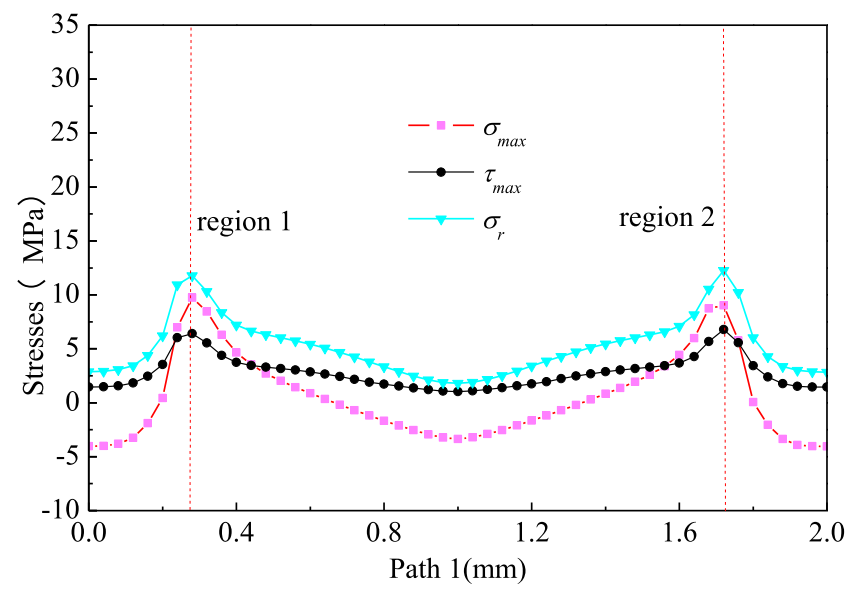

Fig. 3. Stress distribution of path 1.

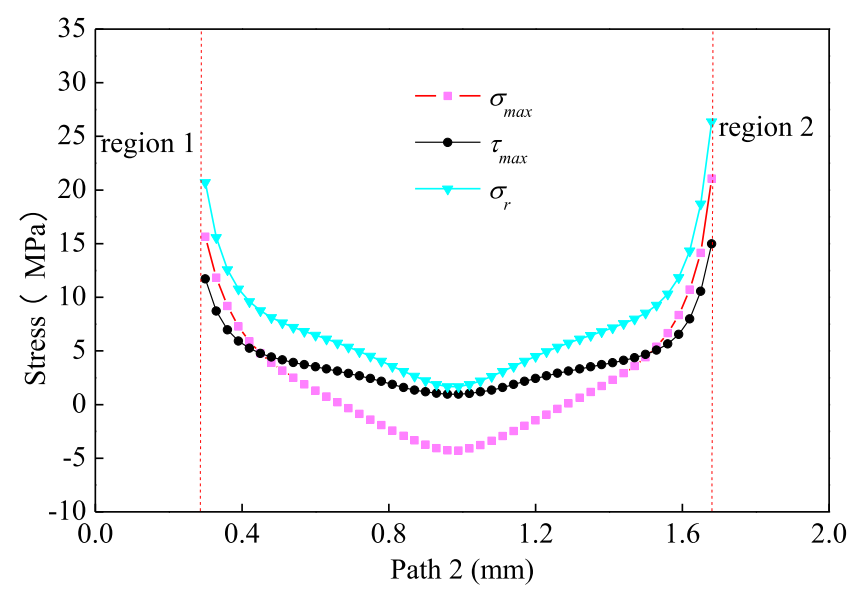

Fig. 4. Stress distribution of path 2 .

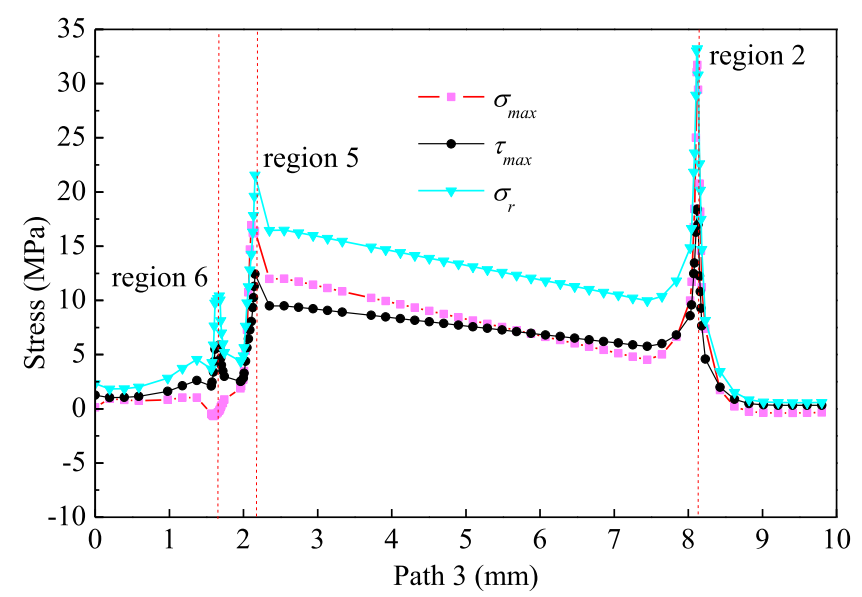

Fig. 5. Stress distribution of path 3 .

cally distributed. In Figure 3, they reach the peak values in brazed joint which is the small transitional arcs on the two terminals of the brazing seam (regions 1 and 2 in Fig. 2). The same conclusion can be also drawn for path 2 in Figure 4, but the maximum normal stress, maximum shear

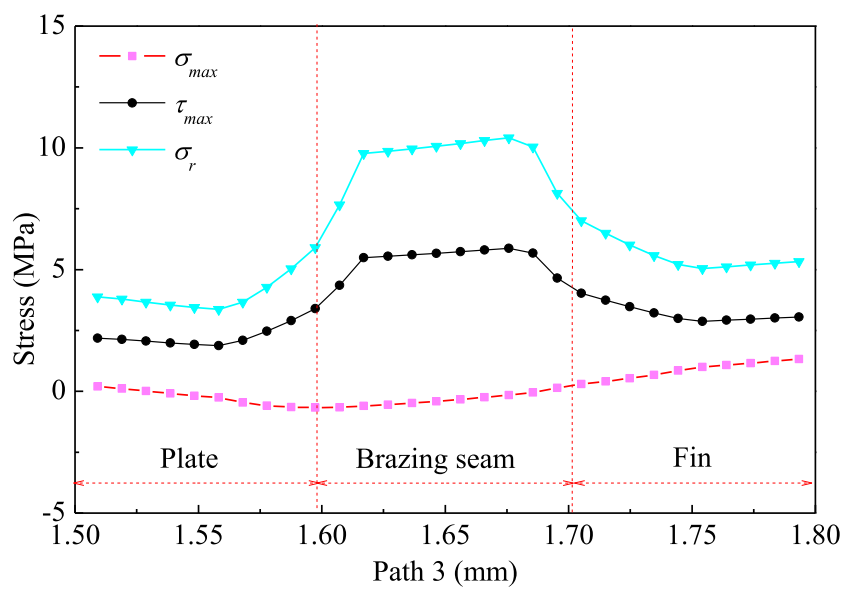

Fig. 6. Stress distribution of the local position in region 6 .

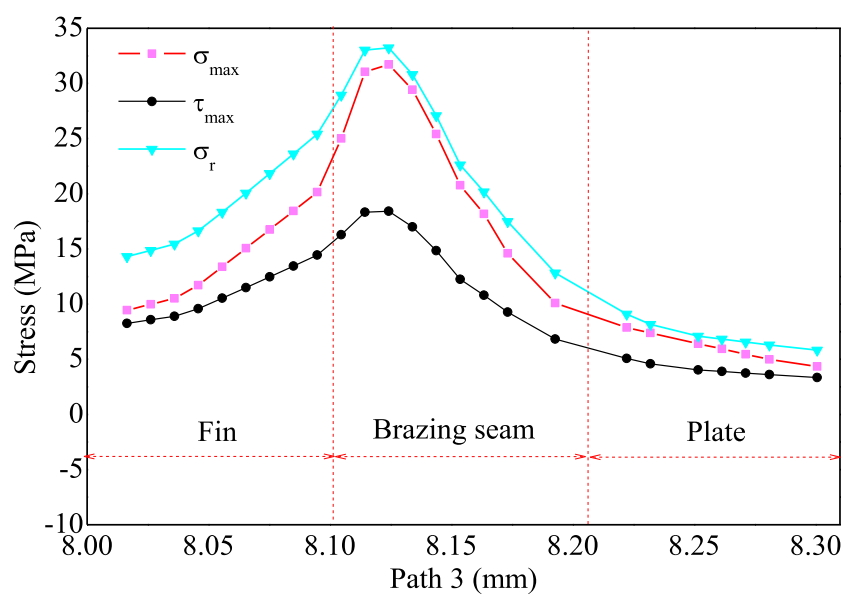

Fig. 7. Stress distribution of the local position in region 2.

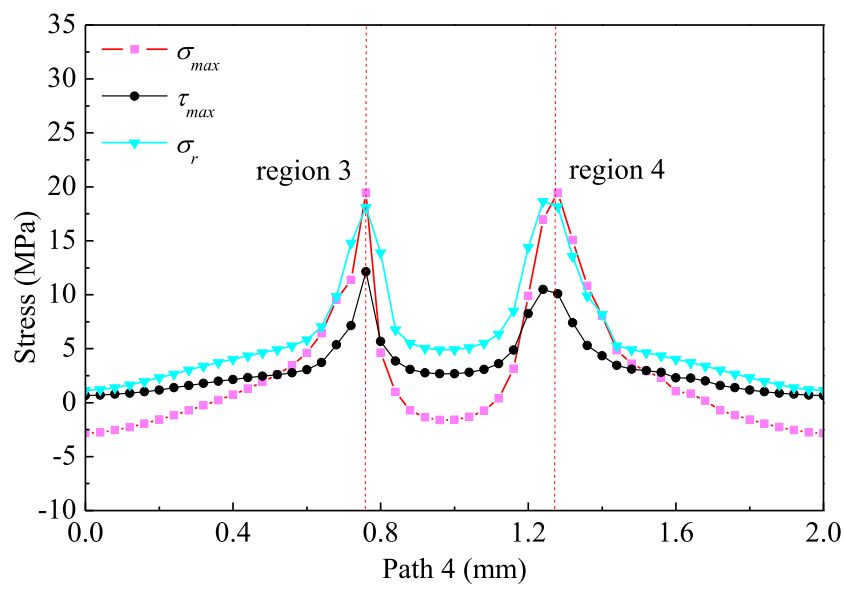

Fig. 8. Stress distribution of path 4 .

stress and equivalent stress are much larger in regions 1 and 2 along the path 2 than that along the path 1 . At the same time, the maximum normal stress is obviously larger than the maximum shear stress in the region of brazed joint near the fin side, while the maximum normal stress is obviously 
smaller than the maximum shear stress in the brazing filler metal layer. Therefore, the main reason of structural damage is the maximum shear stress at the brazing filler metal layer between plate and fin while is the maximum normal stress in the region of brazed joint near the fin side.

Figure 5 depicts the stress distribution of path 3 . The results show that the stresses distribution of maximum normal stress, maximum shear stress and equivalent stress are very complex along the path 3 . The stress gradient of brazed joint (region 2 in Fig. 2), brazing seam (region 6 in Fig. 2) and rectangular region (region 5 in Fig. 2) are much larger, and the maximum normal stress, maximum shear stress and equivalent stress reach the peak value in these regions due to the stress concentration and the mismatching thermal expansion coefficients between AL4004 filler metal and AL3003 base metal. But the peak stress in region 2 is larger than that in regions 5 and 6 . In order to further analyze the stress distribution in regions 2 and 6 , the stress distribution of the local position in regions 2 and 6 (region 2 in Fig. 2b and region 6 in Fig. 2c) are presented in Figures 6 and 7. Figure 6 depicts the distributions of the maximum normal stress, maximum shear stress and equivalent stress in the local position of region 6 . The results show that the maximum normal stress, maximum shear stress and equivalent stress are much larger in the brazing seam between plate and fin than that in the adjacent region due to the mismatching thermal expansion coefficients between AL4004 filler metal and AL3003 base metal. Figure 7 presents the distribution of the maximum normal stress, maximum shear stress and equivalent stress in the local position of region 2 . The results also indicate that the peak stress occurs in brazed joint near the fin side.

Figure 8 exhibits the distributions of the maximum normal stress, maximum shear stress and equivalent stress along path 4 . These results are also obtained that the maximum normal stress, maximum shear stress and equivalent stress reach the peak value, and the stress gradient is much larger in brazed joint (regions 3 and 4 in Fig. 2) due to the stress concentration and the mismatching thermal expansion coefficients between AL4004 filler metal and AL3003 base metal.

To sum up, in the actual operating processes, the maximum normal stress and maximum shear stress along four paths of plate-fin structure are consistent with the equivalent stress based on the von Mises yield criterion and reach the peak value in the brazed joint (regions 1,2, 3 and 4 in Fig. 2), and the stress is larger in brazed joint near the fin side than that in the adjacent region. The brazing seam between the fin and the plate also suffers the larger stress than that in the adjacent region due to the stress concentration and the mismatching thermal expansion coefficients between AL4004 filler metal and AL3003 base metal. This means that the crack failure would occur in the area of brazed joint next to the fin side firstly. At the same time, the structural damage is mainly induced by the maximum shear stress at the brazing filler metal layer between plate and fin while by the maximum normal stress in the region of brazed joint near the fin side. For plate-fin heat exchangers in a large LNG cold-box, when the platefin structure is served under extreme conditions (low temperature and high pressure), the high stress in brazed joint next to the fin side would induce stress crack and result in failure, eventually.

\subsection{The influence of operation parameters for stress}

In Section 3.1, it is stated that the maximum normal stress, maximum shear stress and equivalent stress reach the peak value in the brazed joint of plate-fin structures next to the fin side due to the stress concentration and the mismatching thermal expansion coefficients between AL4004 filler metal and AL3003 base metal. This is likely to lead to a crack failure in these regions. So it is necessary to investigate the stress characteristics of plate-fin structures at the different operation parameters in LNG heat exchanger. In this section, the peak value of maximum normal stress, maximum shear stress and equivalent stress in the stress concentration region of the total plate-fin structures is investigated at the different operation parameters. The peak value of maximum normal stress, maximum shear stress and equivalent stress represented as $\left(\sigma_{\max }\right)_{\max }$, and $\left(\tau_{\max }\right)_{\max }$ and $\left(\sigma_{r}\right)_{\max }$, respectively. In the following content, the peak value of maximum normal stress, maximum shear stress and equivalent stress will be analyzed at the different operation parameters (for example, heat transfer coefficient, fluid temperature and operation pressure) in LNG heat exchanger.

\subsubsection{The influence of heat transfer coefficient}

The heat transfer performance of heat exchanger directly impacts the temperature distribution field of plate-fin structures. The different temperature distribution would induce the different stress characteristics of plate-fin structures in LNG plate-fin heat exchangers. The heat transfer coefficient between the MR or NG and the wall of plate-fin structures is the key parameters to describe the heat transfer performance of LNG heat exchanger. The relation between the stress and the heat transfer coefficient is analyzed in order to investigate the stress characteristics of plate-fin structures at the different heat transfer performance of heat exchanger. Figure 9 presents the data on the peak value of maximum normal stress, maximum shear stress and equivalent stress as a function of the heat transfer coefficient between the NG and the wall of plate-fin structures at temperature difference $\Delta T=5 \mathrm{~K}$ between NG and MR, heat transfer coefficient $h_{\mathrm{MR}}=1 \mathrm{~kW} /\left(\mathrm{m}^{2} \cdot \mathrm{K}\right)$, fluid pressure $P_{\mathrm{NG}}=7.1 \mathrm{MPa}, P_{\mathrm{MR}}=0.4 \mathrm{MPa}$ and $\mathrm{MR}$ temperature $T_{\mathrm{MR}}=150 \mathrm{~K}$. The results indicate that the peak value of maximum normal stress, maximum shear stress and equivalent stress increases slightly as the heat transfer coefficient between the NG and the wall of plate-fin structures increases.

Figure 10 depicts the relation between the peak stress and the heat transfer coefficient between the MR and the wall of plate-fin structures at temperature difference $\Delta T=5 \mathrm{~K}$ between $\mathrm{NG}$ and $\mathrm{MR}$, heat transfer coefficient $h_{\mathrm{NG}}=1.5 \mathrm{~kW} /\left(\mathrm{m}^{2} \cdot \mathrm{K}\right)$, fluid pressure $P_{\mathrm{NG}}=7.1 \mathrm{MPa}$, $P_{\mathrm{MR}}=0.4 \mathrm{MPa}$ and $\mathrm{MR}$ temperature $T_{\mathrm{MR}}=150 \mathrm{~K}$. The results indicate that the peak stress of maximum normal stress, maximum shear stress and equivalent stress decreases slightly with the increase of heat transfer coefficient between 


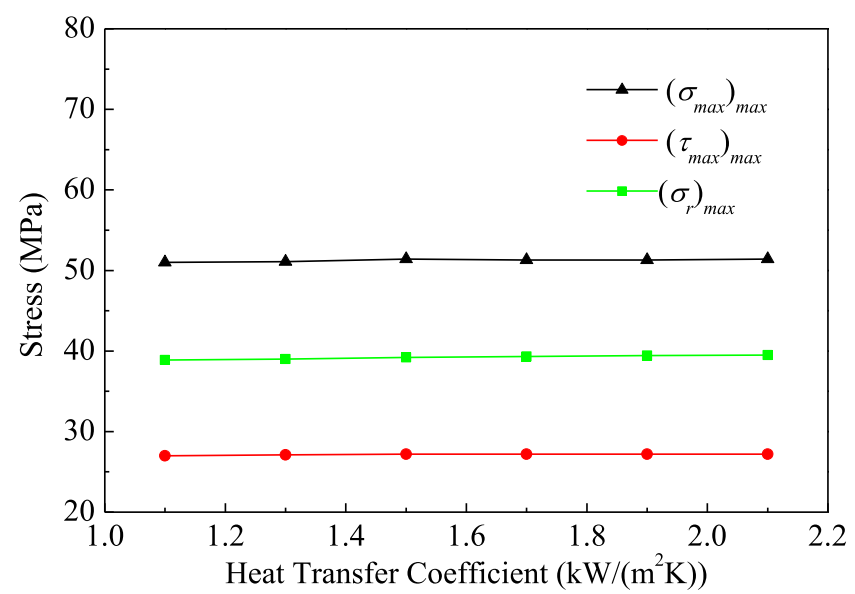

Fig. 9. The peak value of maximum normal stress, maximum shear stress and equivalent stress vs. heat transfer coefficient between the NG and the wall of plate-fin structures.

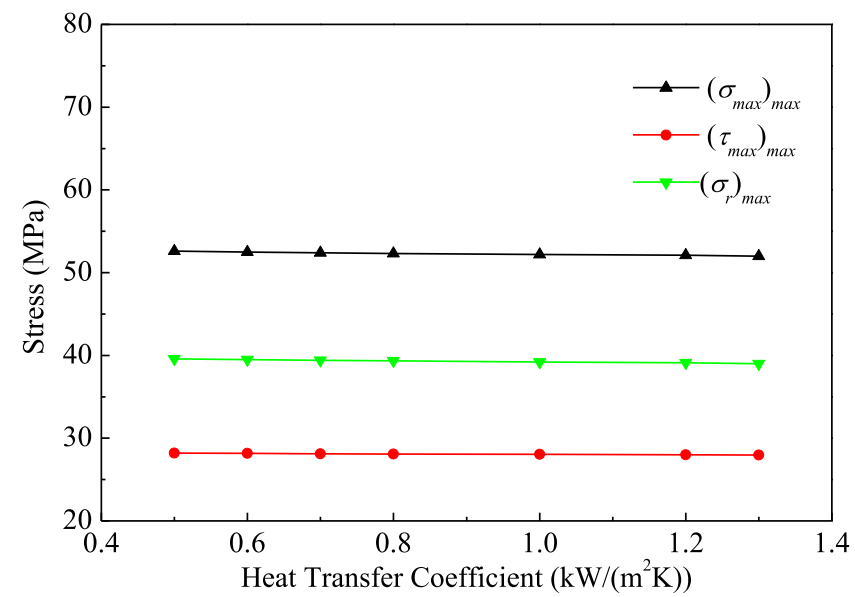

Fig. 10. The peak value of maximum normal stress, maximum shear stress and equivalent stress vs. heat transfer coefficient between the MR and the wall of plate-fin structures.

the MR and the wall of plate-fin structures. This is because the temperature of plate-fin structures reduces slightly with the increase of heat transfer coefficient between the MR and the wall of plate-fin structures and the mismatching of thermal expansion coefficients between AL4004 filler metal and AL3003 base metal reduces with the reduction of temperature.

In other words, the peak value of maximum normal stress, maximum shear stress and equivalent stress is slightly impacted by the heat transfer coefficient between the MR or NG and the wall of plate-fin structures and decreases slightly with the increase of heat transfer coefficient between the MR and the wall of plate-fin structures because that the mismatch of thermal expansion coefficients between AL4004 filler metal and AL3003 base metal reduces with the reduction of temperature of plate-fin structures.

\subsubsection{The influence of fluid temperature}

The variety of the temperature difference between NG and MR will also result in the different stress state in various

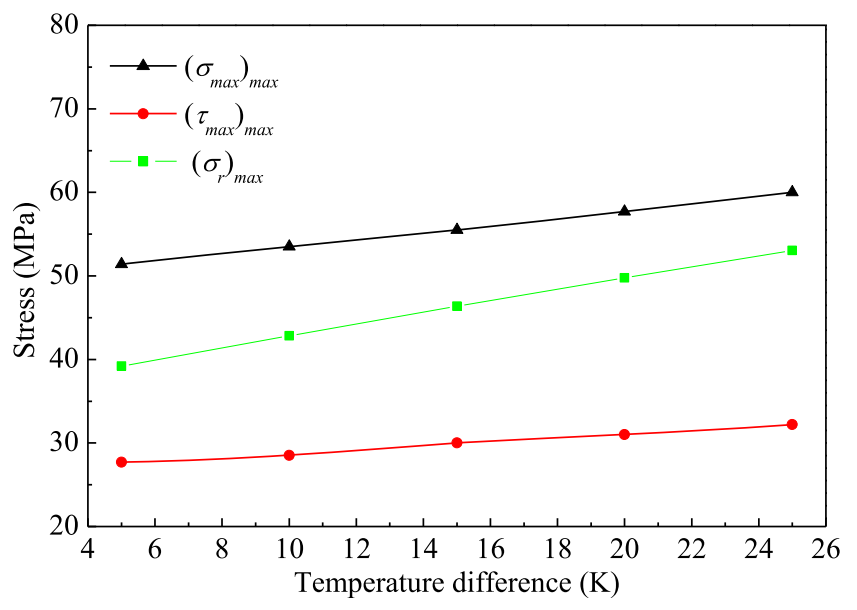

Fig. 11. The peak value of maximum normal stress, maximum shear stress and equivalent stress vs. temperature difference.

design or operation conditions. In this work, the influence of the temperature difference between NG and MR is analyzed for the maximum normal stress, maximum shear stress and equivalent stress of plate-fin structures in a very short length near the NG entrance of liquefied heat exchanger. Figure 11 shows the peak value of maximum normal stress, maximum shear stress and equivalent stress vs. the temperature difference between $\mathrm{NG}$ and $\mathrm{MR}$ for heat transfer coefficient $h_{\mathrm{NG}}=1.5 \mathrm{~kW} /\left(\mathrm{m}^{2} \cdot \mathrm{K}\right), \quad h_{\mathrm{MR}}=$ $1 \mathrm{~kW} /\left(\mathrm{m}^{2} \cdot \mathrm{K}\right)$, fluid pressure $P_{\mathrm{NG}}=7.1 \mathrm{MPa}, P_{\mathrm{MR}}=$ $0.4 \mathrm{MPa}$ and $\mathrm{MR}$ temperature $T_{\mathrm{MR}}=150 \mathrm{~K}$. The peak value of maximum normal stress, maximum shear stress and equivalent stress increases steadily with the increase of the temperature difference between NG and MR, and is obviously impacted by the temperature difference between NG and MR. This is because the thermal expansion coefficients of AL3003 base metal do not match with that of AL4004 filler metal and the large temperature difference between NG and MR results in the increase of temperature gradient in the plate-fin structure. The peak value of maximum normal stress is always larger than that of maximum shear stress at the different temperature between NG and MR. For main cryogenic heat exchanger in a large LNG cold-box, the boiling heat transfer and the condensation heat transfer are performed in the passage of the MR and the NG, respectively. Due to the complexity and instability of the boiling heat transfer and the condensation heat transfer, the temperature difference between NG and MR will vary greatly if the operations are not reasonable for the main cryogenic heat exchanger. This will result in fatigue failure in the brazed joint of plate-fin structures in LNG heat exchanger. And the fatigue failure of plate-fin structures is mainly induced by the maximum normal stress at the different temperature between NG and MR.

At the same time, the stress state of the plate-fin structures is also different along the length direction of plate-fin structures because the NG and MR temperature are various along the length direction of plate-fin structures from the NG entrance to the NG exit. It is necessary to analyze the influence of the NG or MR temperature for the stress characteristics of plate-fin structures along the 


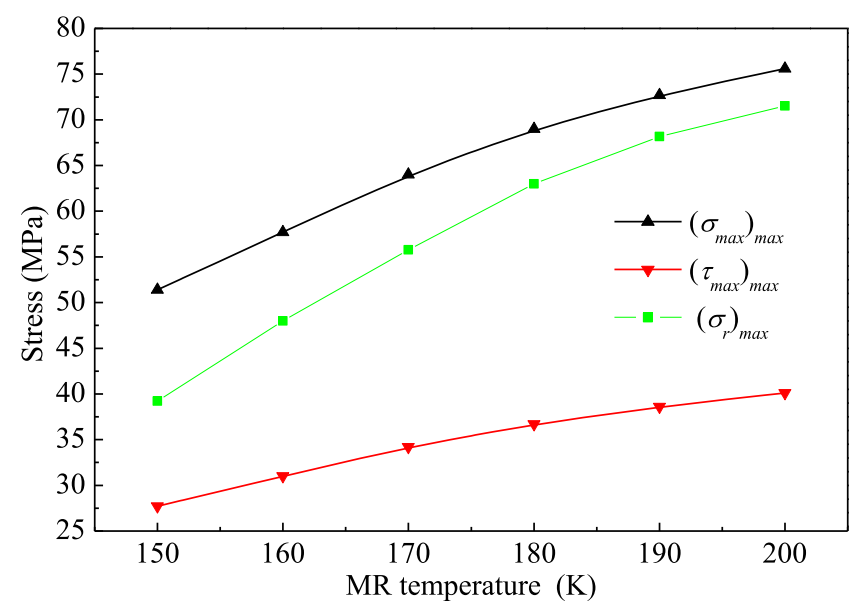

Fig. 12. The peak value of maximum normal stress, maximum shear stress and equivalent stress vs. MR temperature.

length direction of liquefied heat exchanger from the NG entrance to the NG exit. Figure 12 depicts the relation between the peak stress and the MR temperature of the different position along the length direction of liquefied heat exchanger. Figure 12 presents the plots of peak value of maximum normal stress, maximum shear stress and equivalent stress vs. MR temperature. The plots are drawn at temperature difference $\Delta T=5 \mathrm{~K}$ between $\mathrm{NG}$ and MR, heat transfer coefficient $h_{\mathrm{NG}}=1.5 \mathrm{~kW} /\left(\mathrm{m}^{2} \cdot \mathrm{K}\right), h_{\mathrm{MR}}=1$ $\mathrm{kW} /\left(\mathrm{m}^{2} \cdot \mathrm{K}\right)$ and fluid pressure $P_{\mathrm{NG}}=7.1 \mathrm{MPa}, P_{\mathrm{MR}}=0.4$ $\mathrm{MPa}$. The results show that the peak value of maximum normal stress, maximum shear stress and equivalent stress obviously increases as the MR temperature increases. This is because the mismatch of thermal expansion coefficients between AL4004 filler metal and AL3003 base metal is more obvious in high MR temperature than that in lower MR temperature. At the same time, the peak value of maximum normal stress is always larger than that of maximum shear stress at the different MR temperature.

\subsubsection{The influence of operation pressure}

The stress of plate-fin structures is different for the different operation pressures condition. In order to analyze the stress characteristics of plate-fin structures at the different operation pressure condition, the relation between the peak stress and the MR or NG pressure is simulated in this section. Figure 13 depicts the relation between the peak value of maximum normal stress, maximum shear stress and equivalent stress and MR pressure at $\mathrm{NG}$ pressure $P_{\mathrm{NG}}=7.1 \mathrm{MPa}$, temperature difference $\Delta T=5 \mathrm{~K}$ between NG and MR, MR temperature $T_{\mathrm{MR}}=150 \mathrm{~K}$ and heat transfer coefficient $h_{\mathrm{NG}}=1.5 \mathrm{~kW} /$ $\left(\mathrm{m}^{2} \cdot \mathrm{K}\right), h_{\mathrm{MR}}=1 \mathrm{~kW} /\left(\mathrm{m}^{2} \cdot \mathrm{K}\right)$. The results show that the peak value of maximum normal stress, maximum shear stress and equivalent stress increases slightly with the increase of MR pressure. Meanwhile, the peak value of maximum normal stress is also larger than that of maximum shear stress at the different MR pressure.

The peak value of maximum normal stress, maximum shear stress and equivalent stress vs. NG pressure at MR pressure $P_{\mathrm{MR}}=0.4 \mathrm{MPa}$, temperature difference $\Delta T=5 \mathrm{~K}$

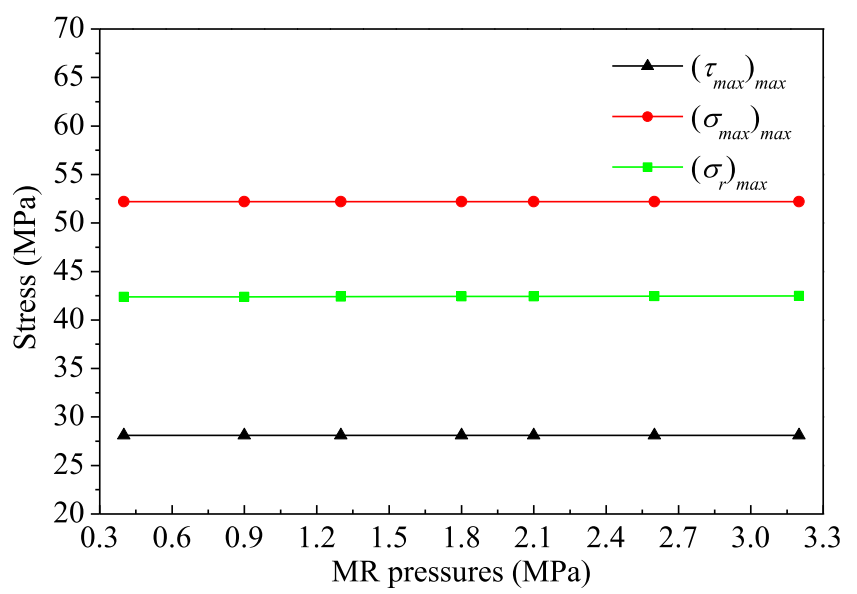

Fig. 13. The peak value of maximum normal stress, maximum shear stress and equivalent stress vs.MR pressures.

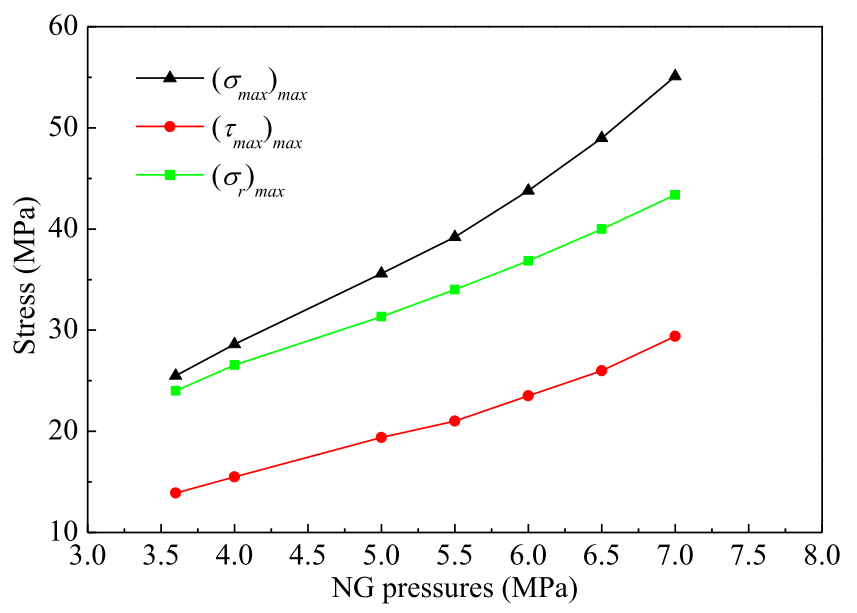

Fig. 14. The peak value of maximum normal stress, maximum shear stress and equivalent stress vs. NG pressures.

between NG and MR, MR temperature $T_{\mathrm{MR}}=150 \mathrm{~K}$ and heat transfer coefficient $h_{\mathrm{NG}}=1.5 \mathrm{~kW} /\left(\mathrm{m}^{2} \cdot \mathrm{K}\right), h_{\mathrm{MR}}=1$ $\mathrm{kW} /\left(\mathrm{m}^{2} \cdot \mathrm{K}\right)$ are presented in Figure 14 . The results show that the peak value of maximum normal stress, maximum shear stress and equivalent stress increases with the increase of NG pressure, and the increase rate is obvious. At the different NG pressure, the peak value of maximum normal stress is also larger than that of maximum shear stress for the whole plate-fin structures in LNG heat exchanger. In other words, the influence of NG pressure for the stress characteristics of plate-fin structures in LNG heat exchanger is induced by the maximum normal stress.

\section{Conclusion}

In this work, the stress characteristics of plate-fin structures in LNG heat exchanger were investigated at the different operation parameters condition. The distribution of maximum normal stress, maximum shear stress and equivalent stress is obtained in this paper. The following conclusions can be drawn from this study: 
- the results obtained by numerical simulation indicate that the maximum normal stress, maximum shear stress and equivalent stress reach the peak values at brazed joint near the fin side. The brazing seam between the fin and the plate also suffers larger stress than that in the adjacent region. The structural failure of plate-fin structures in LNG heat exchanger is mainly induced by the maximum shear stress at the brazing filler metal layer between plate and fin while by the maximum normal stress in the region of brazed joint near the fin side;

- the peak value of maximum normal stress, maximum shear stress and equivalent stress is obviously impacted by the temperature difference between NG and MR in the actual operation process of LNG heat exchanger. And the structural failure of plate-fin structures in LNG heat exchanger is finally induced by the maximum normal stress. In order to ensure the safe and reliable operation of plate-fin structures, the temperature difference between NG and MR needs to be reasonably controlled in main cryogenic heat exchanger which is used in a large-scale LNG cold-box;

- the peak value of maximum normal stress, maximum shear stress and equivalent stress is obviously impacted by the NG pressure while influence of MR pressure is slight in the actual operation process. At the same time, the maximum normal stress is also main factor to result in the structural failure of plate-fin structures at the different NG pressure of LNG heat exchanger.

Acknowledgments. The authors are grateful for the support of the Natural Science Foundation of Gansu Province.

\section{References}

Carey V.P., Mandrusiak G.D. (1986) Annular film flow boiling of liquids in a partially heated, vertical channel with offset strip fins, Int. J. Heat Mass Transf. 29, 6, 927-939.

Jiang W.C., Gong J.M., Tu S.T. (2010) A new cooling method for vacuum brazing of a stainless steel plate-fin structure, Mater. Des. 31, 1, 648-653.

Jiang W.C., Chen H., Gong J.M., Tu S.T. (2011a) Numerical modelling and nanoindentation experiment to study the brazed residual stresses in an X-type lattice truss sandwich structure, Mater. Sci. Eng. A 528, 13, 4715-4722.

Jiang W.C., Wang B.Y., Gong J.M., Tu S.T. (2011b) Finite element analysis of the effect of welding heat input and layer number on residual stress in repair welds for a stainless steel clad plate, Mater. Des. 32, 5, 2851-2857.

Jiang W., Yang B., Gong J.M. et al. (2011c) Effects of clad and base metal thickness on residual stress in the repair weld of a stainless steel clad plate, J. Press. Vessel. Technol. 133, 6, 061401.

Jiang W.C., Zhang Y.C., Woo W. (2012) Using heat sink technology to decrease residual stress in $316 \mathrm{~L}$ stainless steel welding joint: Finite element simulation, Int. J. Press. Vessel. Pip. 92, 56-62.

Khan K.A., Barello R., Muliana A.H., Levesque M. (2011) Coupled heat conduction and thermal stress analyses in particulate composites, Mech. Mater. 43, 10, 608-625.

Kuznetsov V.V., Shamirzaev A.S. (2007) Boiling heat transfer for freon R21 in rectangular minichannel, Heat Transf. Eng. 28, 8, $738-745$.

Ligterink N.E., Hageraats-Ponomareva S.V., Velthuis J.F.M. (2012) Mechanical integrity of PFHE in LNG liquefaction process, in: Barrio M., Venvik H.J. (eds.), 2nd Trondheim Gas Technology Conference, pp. 49-55.

Liu Z., Winterton R. (1991) A general correlation for saturated and subcooled flow boiling in tubes and annuli, based on a nucleate pool boiling equation, Int. J. Heat Mass Transf. 34, 11, 2759-2766.

Ma H., Cai W., Zheng W., Chen J., Yao Y., Jiang Y. (2014) Stress characteristics of plate-fin structures in the cool-down process of LNG heat exchanger, J. Nat. Gas Sci. Eng. 21, 1113-1126.

Ma H., Cai W., Yao Y., Jiang Y. (2016a) Investigation on stress characteristics of plate-fin structures in the heat-up process of LNG heat exchanger, J. Nat. Gas Sci. Eng. , 30, 256-267.

Ma H., Hou C., Yang R., Li C., Ma B., Ren J., Liu Y. (2016b) The influence of structure parameters on stress of plate-fin structures in LNG heat exchanger, J. Nat. Gas Sci. Eng. 34, 85-99.

Manglik R.M., Bergles A.E. (1995) Heat transfer and pressure drop correlations for the rectangular offset strip fin compact heat exchanger, Exp. Therm. Fluid Sci. 10, 2, 171-180.

Mizokami Y., Igari T., Kawashima F., Sakakibara N., Tanihira M., Yuhara T., Hiroe T. (2013) Development of structural design procedure of plate-fin heat exchanger for HTGR, $\mathrm{Nucl}$. Eng. Des. 255, 248-262.

Picard F., Averous D., Joulia X., Barreteau D. (2006) Modelling and dynamic simulation of thermal stresses in brazed plate-fin heat exchanger, 16th European Symposium on Computer Aided Process Engineering and 9th International Symposium on Process Systems Engineering, Vol. 21, pp. 659-664.

Zhao N., Yang Y.Q., Han M., Luo X., Feng G.H., Zhang R.J. (2012) Finite element analysis of pressure on 2024 aluminum alloy created during restricting expansion-deformation heattreatment, Trans. Nonferrous Met. Soc. China 22, 9, 22262232 . 